OPEN ACCESS

Edited by:

Petra Patakova,

University of Chemistry

and Technology in Prague, Czechia

Reviewed by:

Klaas J. Jan Hellingwerf, University of Amsterdam, Netherlands

Anke Neumann,

Karlsruhe Institute of Technology

(KIT), Germany

*Correspondence:

Peter Dürre

peter.duerre@uni-ulm.de

Specialty section:

This article was submitted to

Synthetic Biology,

a section of the journa

Frontiers in Bioengineering and

Biotechnology

Received: 22 January 2021

Accepted: 22 March 2021

Published: 12 April 2021

Citation:

Weitz S, Hermann M, Linder $S$, Bengelsdorf FR, Takors $R$ and Dürre $P$ (2021) Isobutanol Production by Autotrophic Acetogenic Bacteria. Front. Bioeng. Biotechnol. 9:657253. doi: 10.3389/fbioe.2021.657253

\section{Isobutanol Production by Autotrophic Acetogenic Bacteria}

\author{
Sandra Weitz', Maria Hermann ${ }^{2}$, Sonja Linder ${ }^{1}$, Frank R. Bengelsdorf ${ }^{1}$, Ralf Takors ${ }^{2}$ and \\ Peter Dürre ${ }^{1 *}$ \\ ${ }^{1}$ Institut für Mikrobiologie und Biotechnologie, Universität UIm, Ulm, Germany, ${ }^{2}$ Institut für Bioverfahrenstechnik, Universität \\ Stuttgart, Stuttgart, Germany
}

Two different isobutanol synthesis pathways were cloned into and expressed in the two model acetogenic bacteria Acetobacterium woodii and Clostridium ljungdahlii. A. woodii is specialized on using $\mathrm{CO}_{2}+\mathrm{H}_{2}$ gas mixtures for growth and depends on sodium ions for ATP generation by a respective ATPase and Rnf system. On the other hand, C. ljungdahlii grows well on syngas $\left(\mathrm{CO}+\mathrm{H}_{2}+\mathrm{CO}_{2}\right.$ mixture) and depends on protons for energy conservation. The first pathway consisted of ketoisovalerate ferredoxin oxidoreductase (Kor) from Clostridium thermocellum and bifunctional aldehyde/alcohol dehydrogenase (AdhE2) from C. acetobutylicum. Three different kor gene clusters are annotated in $C$. thermocellum and were all tested. Only in recombinant $A$. woodii strains, traces of isobutanol could be detected. Additional feeding of ketoisovalerate increased isobutanol production to $2.9 \mathrm{mM}$ under heterotrophic conditions using kor3 and to $1.8 \mathrm{mM}$ under autotrophic conditions using kor2. In C. ljungdahlii, isobutanol could only be detected upon additional ketoisovalerate feeding under autotrophic conditions. kor3 proved to be the best suited gene cluster. The second pathway consisted of ketoisovalerate decarboxylase from Lactococcus lactis and alcohol dehydrogenase from Corynebacterium glutamicum. For increasing the carbon flux to ketoisovalerate, genes encoding ketol-acid reductoisomerase, dihydroxy-acid dehydratase, and acetolactate synthase from $C$. ljungdahlii were subcloned downstream of adhA. Under heterotrophic conditions, A. woodii produced $0.2 \mathrm{mM}$ isobutanol and $0.4 \mathrm{mM}$ upon additional ketoisovalerate feeding. Under autotrophic conditions, no isobutanol formation could be detected. Only upon additional ketoisovalerate feeding, recombinant $A$. woodii produced $1.5 \mathrm{mM}$ isobutanol. With $C$. ljungdahlii, no isobutanol was formed under heterotrophic conditions and only $0.1 \mathrm{mM}$ under autotrophic conditions. Additional feeding of ketoisovalerate increased these values to $1.5 \mathrm{mM}$ and $0.6 \mathrm{mM}$, respectively. A further increase to $2.4 \mathrm{mM}$ and $1 \mathrm{mM}$, respectively, could be achieved upon inactivation of the ilvE gene in the recombinant $C$. ljungdahlii strain. Engineering the coenzyme specificity of $\| v \mathrm{~V}$ of $C$. ljungdahlii from NADPH to NADH did not result in improved isobutanol production.

Keywords: Acetobacterium woodii, acetogens, Clostridium ljungdahlii, gas fermentation, isobutanol production, syngas 


\section{INTRODUCTION}

Isobutanol is an important platform chemical, representing an app. one billion US \$ market in 2019. The compound is mainly used in solvents and coatings, as a chemical intermediate, or as a biofuel (gasoline additive). Synthesis is chemically achieved by hydroformylation of propylene, followed by hydrogenation of the formed aldehyde, but bio-based processes have been developed by companies Gevo Inc. (Douglas County, CO) and Butamax Advanced Biofuels LLC (Wilmington, DE; joint venture of BP and DuPont). The share of bio-based isobutanol is expected to rise in the near future significantly compared to the synthetic compound. A number of microorganisms have been engineered for isobutanol production, including aerobic and anaerobic bacteria as well as Saccharomyces cerevisiae (Chen and Liao, 2016). Gevo is using a recombinant yeast for its corn-based process, but details have not yet been disclosed. A landmark publication reported genetically engineered isobutanol formation by modification of amino acid synthesis pathways (Atsumi et al., 2008). 2-Ketoisovalerate, an intermediate in valine and isoleucine biosynthesis, was first decarboxylated by e.g., KivD from Lactococcus lactis and then the formed aldehyde was reduced to isobutanol by an alcohol dehydrogenase (e.g., Adh2 from Saccharomyces cerevisiae) (Figure 1). A natural pathway for production is based on the enzyme ketoisovalerate ferredoxin oxidoreductase (Kor), which was first found and characterized

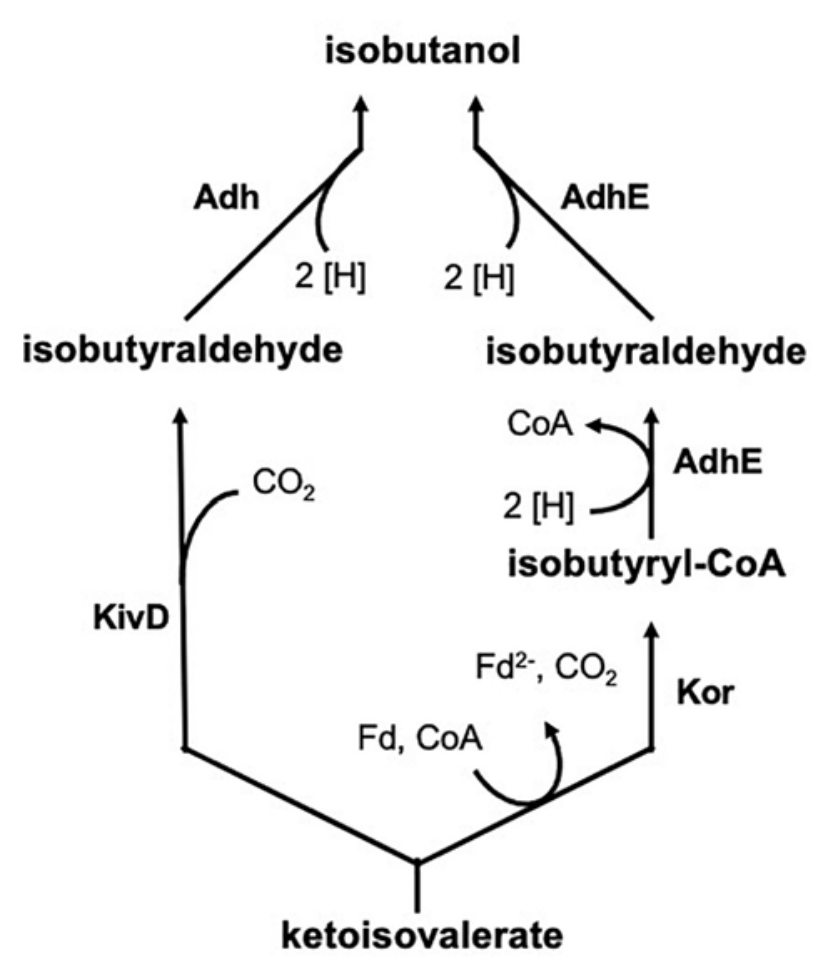

FIGURE 1 | Formation of isobutanol by the enzymes KivD (ketoisovalerate decarboxylase) and Adh (alcohol dehydrogenase) or Kor (ketoisovalerate ferredoxin oxidoreductase) and AdhE (bifunctional aldehyde/alcohol dehydrogenase) from ketoisovalerate, the precursor of valine. in hyperthermophilic archaea, where it is involved in branchedchain amino acid degradation and biosynthesis (Heider et al., 1996). This isobutanol synthesis pathway (Figure 1) was shown to be active in e.g., Clostridium thermocellum (Lin et al., 2015).

Using biological production with recombinant strains, high isobutanol titers in typical fermentation setups were obtained with e.g., E. coli (22 g/l; Atsumi et al., 2008), Corynebacterium glutamicum (13 g/l; Blombach et al., 2011), Clostridium thermocellum (5.4 g/l; Lin et al., 2015), Geobacillus thermoglucosidasius (3.3 g/l; Lin et al., 2014), S. cerevisiae (2.1 g/l; Wess et al., 2019), and Ralstonia eutropha (0.03 g/l; Black et al., 2018). All these processes used sugar or cellulose as a carbon source. Cheaper substrates would be $\mathrm{CO}_{2}$ (in combination with a reductant) or $\mathrm{CO}$, which are also waste and greenhouse gases. A photosynthetic isobutanol production of up to $0.9 \mathrm{~g} / \mathrm{l}$ from $\mathrm{CO}_{2}$ and solar energy has been reported for Synechocystis PCC 6803 (Miao et al., 2018). The electrochemical conversion of $\mathrm{CO}_{2}$ and water to formate was coupled with formate-dependent growth of recombinant cells of the aerobic "Knallgas" bacterium $R$. eutropha, yielding up to $0.85 \mathrm{~g}$ isobutanol/l (Li et al., 2012). However, some challenges still remain for $\mathrm{CO}_{2}$-based biological isobutanol formation compared to the non-biological production (Brigham, 2019).

Here, we report an approach to isobutanol synthesis using two anaerobic bacteria, which became model organisms of the so-called acetogens: Acetobacterium woodii, growing on $\mathrm{CO}_{2} / \mathrm{H}_{2}$, and Clostridium ljungdahlii, growing on syngas (a mixture of mostly $\mathrm{CO}$ and $\mathrm{H}_{2}$ ).

\section{MATERIALS AND METHODS}

\section{Bacterial Strains and Plasmids}

Acetobacterium woodii (DSM 1030) and Clostridium ljungdahlii (DSM13583) were obtained from the DSMZ (Deutsche Sammlung von Mikroorganismen und Zellkulturen $\mathrm{GmbH}$, Brunswick, Germany). Escherichia coli XL1-Blue MRF' [ $\Delta(m c r A) 183 \Delta(m c r C B-h s d S M R-m r r) 173$ endA1 supE44 thi1] stemmed from Stratagene (La Jolla, CA). All plasmids used in this study are listed in Table $\mathbf{1 .}$

\section{Media and Growth Conditions}

Escherichia coli was cultivated aerobically in LB (Luria-Bertani) medium (per l: tryptone $10 \mathrm{~g}$, yeast extract $5 \mathrm{~g}, \mathrm{NaCl} 10 \mathrm{~g}$ ) (Green and Sambrook, 2012) at $37^{\circ} \mathrm{C}$ on a rotary shaker (175 rpm). For generation of competent cells, E. coli was grown in modified SOB (Super Optimal Broth; per l: tryptone $20 \mathrm{~g}$, yeast extract $5 \mathrm{~g}, \mathrm{NaCl} 0.5 \mathrm{~g}, \mathrm{KCl} 1.92 \mathrm{~g}, \mathrm{MgCl}_{2} \times 6 \mathrm{H}_{2} \mathrm{O} 2.03 \mathrm{~g}$ ) (Green and Sambrook, 2012).

Basal medium for $A$. woodii was modified from Balch et al. (1977) and contained per l: $\mathrm{KH}_{2} \mathrm{PO}_{4} 0.33 \mathrm{~g}, \mathrm{~K}_{2} \mathrm{HPO}_{4} 0.45 \mathrm{~g}$, $\mathrm{MgSO}_{4} \times 7 \mathrm{H}_{2} \mathrm{O} 0.33 \mathrm{~g}, \mathrm{NH}_{4} \mathrm{Cl} 1 \mathrm{~g}$, yeast extract $2 \mathrm{~g}$, L-cysteine$\mathrm{HCl} \times \mathrm{H}_{2} \mathrm{O} 0.5 \mathrm{~g}$, resazurin $1 \mathrm{mg}$. To this solution, $20 \mathrm{ml}$ of trace element solution (per l: nitrilotriacetic acid $1.5 \mathrm{~g}, \mathrm{MgSO}_{4} \times 7$ $\mathrm{H}_{2} \mathrm{O} 3 \mathrm{~g}, \mathrm{MnSO}_{4} \times \mathrm{H}_{2} \mathrm{O} 0.5 \mathrm{~g}, \mathrm{NaCl}_{1} \mathrm{~g}, \mathrm{FeSO}_{4} \times 7 \mathrm{H}_{2} \mathrm{O} 0.1 \mathrm{~g}$, $\mathrm{CoSO}_{4} \times 7 \mathrm{H}_{2} \mathrm{O} 0.18 \mathrm{~g}, \mathrm{CaCl}_{2} \times 2 \mathrm{H}_{2} \mathrm{O} 0.1 \mathrm{~g}, \mathrm{ZnSO}_{4} \times 7$ $\mathrm{H}_{2} \mathrm{O} 0.18 \mathrm{~g}, \mathrm{CuSO}_{4} \times 5 \mathrm{H}_{2} \mathrm{O} 0.01 \mathrm{~g}, \mathrm{KAl}\left(\mathrm{SO}_{4}\right)_{2} \times 12 \mathrm{H}_{2} \mathrm{O}$ 
TABLE 1 | Plasmids used in this study.

\begin{tabular}{|c|c|c|}
\hline Plasmid & Relevant features & References \\
\hline pJUL34 & $\begin{array}{l}\text { kivD from } L \text {. lactis, } P_{\text {tuf }} \text { from } \\
\text { L. lactis, adhA from } \\
\text { Corynebacterium } \\
\text { glutamicum; aph3; sacB, } \\
\text { replicon repBL1 for } \\
\text { Corynebacterium }\end{array}$ & $\begin{array}{l}\text { Gift from Bastian Blombach } \\
\text { (Technical University of } \\
\text { Munich, Germany) and } \\
\text { Bernhard Eikmanns } \\
\text { (University of Ulm, } \\
\text { Germany) }\end{array}$ \\
\hline $\begin{array}{l}\text { pMTL007- } \\
\text { E2_ilvE }\end{array}$ & $\begin{array}{l}\text { ColE1 ori- }{ }^{-} \text {pCB102 } \text { ori }^{+} \text {, } \\
\text { catP, lacZ, ItrA, oriT, Pfdx, } \\
\text { ermB, traJ, } \\
\text { ClosTron }{ }^{T M} \text { plasmid to } \\
\text { inactivate ilvE in the } \\
\text { genome of } C . \text { ljungdahlii }\end{array}$ & $\begin{array}{l}\text { This study, } \\
\text { ATUM, Newark, CA, } \\
\text { United States }\end{array}$ \\
\hline pMTL83151 & $\begin{array}{l}\text { catP, ColE1 ori- , lacZ, } \\
\text { pCB102 ori }{ }^{+} \text {, traJ }\end{array}$ & Heap et al., 2009 \\
\hline $\begin{array}{l}\text { pMTL83151__ } \\
\text { ptaack_aacht_cac }\end{array}$ & $\begin{array}{l}\text { pMTL83151, } P_{\text {pta-ack }} \text { and } \\
\text { adhE2 from } \\
\text { C. acetobutylicum; abfD } \\
\text { from C. scatologenes, crt, } \\
\text { hbd, and thlA from } \\
\text { C. acetobutylicum }\end{array}$ & This study \\
\hline pKAIA & $\begin{array}{l}\text { pMTL83151, } P_{\text {pta-ack from }} \\
\text { C. ljungdahlii, kivD from } \\
\text { L. lactis, adhA from } \\
\text { Corynebacterium } \\
\text { glutamicum, ilvC, ilvD, and } \\
\text { alsS from C. ljungdahlii }\end{array}$ & This study \\
\hline pKAI $\left.\right|_{N A D H A}$ & $\begin{array}{l}\text { pMTL83151 } P_{\text {pta-ack }} \text { from } \\
\text { C. ljungdahlii, kivD from } \\
\text { L. lactis, adhA from } \\
\text { C. glutamicum, ilvD and } \\
\text { alsS from C. ljungdahlii, } \\
\text { ilvC }{ }^{P 2 D 1-A 1} \text { from E. coli, } \\
\text { codon optimized for } \\
\text { clostridia }\end{array}$ & $\begin{array}{l}\text { This study, } \\
\text { Thermo Fisher Scientific } \\
\text { GENEART GmbH, } \\
\text { Regensburg, Germany, } \\
\text { Brinkmann-Chen et al., } \\
2013\end{array}$ \\
\hline pKOR2 & $\begin{array}{l}\text { pMTL83151, P Pta-ack from } \\
\text { C. ljungdahlii, adhE2 from } \\
\text { C. acetobutylicum, kor2 } \\
\text { from C. thermocellum }\end{array}$ & This study \\
\hline pKOR3 & $\begin{array}{l}\text { PMTL83151, } P_{\text {pta-ack from }} \\
\text { C. ljungdahlii, adhE2 from } \\
\text { C. acetobutylicum, kor3 } \\
\text { from C. thermocellum }\end{array}$ & This study \\
\hline
\end{tabular}

$0.02 \mathrm{~g}, \mathrm{H}_{3} \mathrm{BO}_{3} 0.01 \mathrm{~g}, \mathrm{Na}_{2} \mathrm{MoO}_{4} \times 2 \mathrm{H}_{2} \mathrm{O} 0.01 \mathrm{~g}, \mathrm{NiCl}_{2} \times 6$ $\mathrm{H}_{2} \mathrm{O} 0.03 \mathrm{~g}, \mathrm{Na}_{2} \mathrm{SeO}_{3} \times 5 \mathrm{H}_{2} \mathrm{O} 0.3 \mathrm{mg}, \mathrm{Na}_{2} \mathrm{WO}_{4} \times 2 \mathrm{H}_{2} \mathrm{O}$ $0.4 \mathrm{mg}$ ) and $20 \mathrm{ml}$ vitamin solution (per l: biotin $2 \mathrm{mg}$, folic acid $2 \mathrm{mg}$, pyridoxine- $\mathrm{HCl} 10 \mathrm{mg}$, thiamine- $\mathrm{HCl} 5 \mathrm{mg}$, riboflavin $5 \mathrm{mg}$, nicotinic acid $5 \mathrm{mg}$, D-Ca-pantothenate $5 \mathrm{mg}$, vitamin $\mathrm{B}_{12} 0.1 \mathrm{mg}, \mathrm{p}$-aminobenzoic acid $5 \mathrm{mg}$, lipoic acid $5 \mathrm{mg}$ (DSMZ_Medium141-1.pdf, ${ }^{1}$ ) were added. Media were prepared under strictly anaerobic conditions. Heterotrophic growth was performed with $40 \mathrm{mM}$ fructose as a carbon source under an atmosphere consisting of $\mathrm{N}_{2}(80 \%)$ and $\mathrm{CO}_{2}(20 \%)$, autotrophic growth with a $\mathrm{CO}_{2}+\mathrm{H}_{2}$ gas mixture $(33 \%+67 \%)$, both at $30^{\circ} \mathrm{C}$.

Clostridium ljungdahlii was cultivated in a modified medium described by Tanner et al. (1993). It contained per 1: 2-(Nmorpholino) ethanesulfonic acid $20 \mathrm{~g}$, yeast extract $0.5 \mathrm{~g}$,

\footnotetext{
${ }^{1}$ https://www.dsmz.de/collection/catalog/details/culture/DSM-4553
}

L-cysteine- $\mathrm{HCl} \times \mathrm{H}_{2} \mathrm{O} 1 \mathrm{~g}$, resazurin $1 \mathrm{mg}$. To this solution, $25 \mathrm{ml}$ of mineral salts solution (per $\mathrm{l}: \mathrm{CaCl}_{2} \times 2 \mathrm{H}_{2} \mathrm{O} 4 \mathrm{~g}, \mathrm{KCl} 10 \mathrm{~g}$, $\mathrm{KH}_{2} \mathrm{PO}_{4} 10 \mathrm{~g}, \mathrm{MgSO}_{4} \times 7 \mathrm{H}_{2} \mathrm{O} 20 \mathrm{~g}, \mathrm{NaCl} 80 \mathrm{~g}, \mathrm{NH}_{4} \mathrm{Cl} 100 \mathrm{~g}$ ), $10 \mathrm{ml}$ of modified trace element solution (American Type Culture Collection (ATCC); $; 1754$ PETC medium) (per l: nitrilotriacetic acid $2 \mathrm{~g}, \mathrm{MnSO}_{4} \times \mathrm{H}_{2} \mathrm{O} 0.5 \mathrm{~g}, \mathrm{Fe}\left(\mathrm{SO}_{4}\right)_{2}\left(\mathrm{NH}_{4}\right)_{2} \times 6 \mathrm{H}_{2} \mathrm{O} 0.8 \mathrm{~g}$, $\mathrm{CoCl}_{2} \times 6 \mathrm{H}_{2} \mathrm{O} 0.2 \mathrm{~g}, \mathrm{ZnSO}_{4} \times 7 \mathrm{H}_{2} \mathrm{O} 1 \mathrm{mg}, \mathrm{CuCl}_{2} \times 2 \mathrm{H}_{2} \mathrm{O}$ $20 \mathrm{mg}, \mathrm{NiCl}_{2} \times 6 \mathrm{H}_{2} \mathrm{O} 20 \mathrm{mg}, \mathrm{Na}_{2} \mathrm{MoO}_{4} \times 2 \mathrm{H}_{2} \mathrm{O} 20 \mathrm{mg}$, $\mathrm{Na}_{2} \mathrm{SeO}_{3} \times 5 \mathrm{H}_{2} \mathrm{O} 20 \mathrm{mg}, \mathrm{Na}_{2} \mathrm{WO}_{4} \times 2 \mathrm{H}_{2} \mathrm{O} 20 \mathrm{mg}$ ), and $10 \mathrm{ml}$ vitamin solution (per l: biotin $2 \mathrm{mg}$, folic acid $2 \mathrm{mg}$, pyridoxine- $\mathrm{HCl} 10 \mathrm{mg}$, thiamine- $\mathrm{HCl} 5 \mathrm{mg}$, riboflavin $5 \mathrm{mg}$, nicotinic acid $5 \mathrm{mg}$, D-Ca-pantothenate $5 \mathrm{mg}$, vitamin $\mathrm{B}_{12}$ $5 \mathrm{mg}, \mathrm{p}$-aminobenzoic acid $5 \mathrm{mg}$, and lipoic acid $5 \mathrm{mg}$ ) were added. Media were prepared under strictly anaerobic conditions. Heterotrophic growth was performed with $40 \mathrm{mM}$ fructose as a carbon source under an atmosphere consisting of $\mathrm{N}_{2}(80 \%)$ and $\mathrm{CO}_{2}(20 \%)$, autotrophic growth with a syngas mixture $(50 \% \mathrm{CO}$, $45 \% \mathrm{H}_{2}$, and $5 \mathrm{CO}_{2}$ ), both at $37^{\circ} \mathrm{C}$.

For cultivation of $A$. woodii and C. ljungdahlii on solid media, a modified version of yeast tryptone fructose medium (Leang et al., 2013) was used (per l: yeast extract $10 \mathrm{~g}$, tryptone $16 \mathrm{~g}$, fructose $5 \mathrm{~g}, \mathrm{NaCl} 4 \mathrm{~g}$, L-cysteine- $\mathrm{HCl} \times \mathrm{H}_{2} \mathrm{O} 1 \mathrm{~g}$, resazurin $1 \mathrm{mg}$, agar $15 \mathrm{~g}$ ). Agar plates were poured using anaerobic water in an anaerobic cabinet containing a $\mathrm{N}_{2}: \mathrm{H}_{2}(95: 5 \%)$ gas atmosphere. Cell suspensions were dripped on plates and spread using glass beads. A. woodii cells were incubated at $30^{\circ} \mathrm{C}$ and C. ljungdahlii cells at $37^{\circ} \mathrm{C}$ in an incubator located in the anaerobic cabinet.

For selection of antibiotic-resistant strains, the following concentrations were used per $\mathrm{ml}$ : ampicillin $100 \mathrm{mg}$, clarithromycin $2.5 \mathrm{mg}$, chloramphenicol $30 \mathrm{mg}$, kanamycin $50 \mathrm{mg}$, thiamphenicol $7.5 \mathrm{mg}$.

\section{Analytical Methods}

Cell growth was monitored offline by measuring the optical density at $600 \mathrm{~nm}$ (Ultrospec 3100, Amersham Bioscience Europe $\mathrm{GmbH}$, Freiburg, Germany) in 1-ml cuvettes (width $1 \mathrm{~cm}$ ).

Ethanol, isobutanol, and isoamyl alcohol were determined using gas chromatograph (GC) "Clarus 680" (PerkinElmer, PerkinElmer, Waltham, MA, United States). GC was equipped with an Elite-FFAP column (i Ø $0.32 \mathrm{~mm} \times 30 \mathrm{~m}$ ). $\mathrm{H}_{2}$ was the carrier gas $\left(2.25 \mathrm{ml} \mathrm{min}^{-1}, 100^{\circ} \mathrm{C}\right)$, injector temperature was $225^{\circ} \mathrm{C}$, split 1:20, and flame ionization detector temperature was $300^{\circ} \mathrm{C}$. Detector gases were synthetic air $\left(450 \mathrm{ml} \mathrm{min}^{-1}\right)$ and $\mathrm{H}_{2}\left(45 \mathrm{ml} \mathrm{min}{ }^{-1}\right)$. A temperature profile was predefined: $90^{\circ} \mathrm{C}$ for $2 \mathrm{~min}, 40^{\circ} \mathrm{C} \mathrm{m^{-1 }}$ increasing steps to $250^{\circ} \mathrm{C}$ (constant for $1 \mathrm{~min})$. Supernatant $(0.48 \mathrm{ml})$ was acidified with $0.02 \mathrm{~mL}$ of $2 \mathrm{M}$ $\mathrm{HCl} .1 \mathrm{ml}$ was injected into the GC. Calibration was performed using defined standards of the individual components.

Acetate, 2,3-butanediol, fructose, and ketoisovalerate were determined using high performance liquid chromatography (Agilent 1260 Infinity Series HPLC, Agilent Technologies, Santa Clara, CA) equipped with a refractive index detector (for 2,3butanediol, fructose, ketoisovalerate) operating at $35^{\circ} \mathrm{C}$ and a diode array detector (for acetate) at room temperature. The "CSChromatographie organic acid column” (CS-Chromatographie

\footnotetext{
${ }^{2}$ https://www.lgcstandards-atcc.org/products/all/55383.aspx\#culturemethod
} 
Service GmbH, Langerwehe, Germany) was kept at $40^{\circ} \mathrm{C} .5 \mathrm{mM}$ $\mathrm{H}_{2} \mathrm{SO}_{4}$ was used as mobile phase with a flow rate of $0.7 \mathrm{ml} \mathrm{min}{ }^{-1}$. $20 \mu \mathrm{l}$ of supernatant were injected into the HPLC system for determination of compounds.

\section{DNA Isolation}

Bacterial genomic DNA was isolated using the "MasterPure ${ }^{\mathrm{TM}}$ Gram-Positive DNA Purification Kit” (Epicentre, Madison, WI, United States). 2-mL Samples of late exponential cultures were centrifuged $\left(18,000 \mathrm{~g}, 30 \mathrm{~min}, 4^{\circ} \mathrm{C}\right)$ and further processed according to the manufacturer's instructions. Isolation of plasmid DNA from E. coli strains was performed with the "Zyppy ${ }^{\mathrm{TM}}$ Plasmid Miniprep Kit" (ZYMO Research Europe GmbH, Freiburg, Germany). 4-ml Samples of overnight cultures were centrifuged $(18,000 \mathrm{~g}, 1 \mathrm{~min})$ and further processed according to the manufacturer's instructions. In case of $A$. woodii and C. ljungdahlii, $2 \mathrm{ml}$ were sampled and centrifuged $(18,000 \mathrm{~g}$, $30 \mathrm{~min}, 4^{\circ} \mathrm{C}$ ). The cell pellet was suspended in $600 \mu \mathrm{l}$ Tris $-\mathrm{HCl}$ (20 mM, pH 7). For effective lysis, $60 \mu \mathrm{l}$ lysozyme $\left(20 \mathrm{mg} \mathrm{ml}^{-1}\right)$ were added, and the solution was incubated for $1 \mathrm{~h}$ at $37^{\circ} \mathrm{C}$ before proceeding according to the manufacturer's instructions.

DNA from C. thermocellum DSM 1313 was purchased from the DSMZ (Deutsche Sammlung von Mikroorganismen und Zellkulturen GmbH, Brunswick, Germany).

Sequencing of DNA was performed by GATC Biotech AG (Constance, Germany).

\section{Plasmid Construction}

Standard molecular cloning techniques were performed according to established protocols (Green and Sambrook, 2012). In C. thermocellum, three gene clusters encoding a putative ketoisovalerate ferredoxin oxidoreductase (Kor) are annotated [kor1 (Clo1313_0020-0023), kor2 (Clo1313_03820385), kor3 (Clo1313_1353-1356)]. kor1 was PCR-amplified using primers clo0020T_fwd and clo0020T_rev, kor2 was PCR-amplified using primers clo0382T_fwd and clo0382T_rev, and kor3 was PCR-amplified using primers clo1353T_fwd and clo1353T_rev. Then, each fragment was subcloned into the pMTL83151 backbone (Heap et al., 2009), together (upstream) with the also PCR-amplified $\mathrm{P}_{\text {pta-ack }}$ promoter from C. ljungdahlii (primers: Ptaack_fwd and Ptaack_rev) and the gene encoding bifunctional butyraldehyde/butanol dehydrogenase AdhE2 from C. acetobutylicum [primers: adhE2_pka_fwd and adhE2_pka_rev; plasmid pMTL83151_ptaack_aacht_cac (Supplementary Figure 1)]. All primers used are listed in Table 2. Subcloning was performed by in-fusion cloning using the NEBuilder Assembly Tool (New England Biolabs Inc., Ipswich, MA, United States; ${ }^{3}$ ). The resulting plasmids pKOR1, pKOR2, and pKOR3 are shown in Supplementary Figure 2. pMTL83151 was kindly provided by Nigel Minton (University of Nottingham, United Kingdom).

The plasmids constructed for elucidation of the ketoisovalerate decarboxylase pathway were also based on the

\footnotetext{
${ }^{3}$ https://international.neb.com/products/e5520-nebuilder-hifi-dna-assemblycloning-kit\#ProductInformation
}

pMTL83151 backbone. The kivD gene from L. lactis was PCRamplified using primers kivd_fwd_XhoI and kivd_rev_Eco81I (making use of the inserted restriction sites for subcloning), adhA from C. glutamicum was PCR-amplified using primers adhA_fwd_XhoI and adhA_rev_NheI (making use of the inserted restriction sites for subcloning). DNA source for amplification was plasmid pJUL34 (Supplementary Figure 3), which was kindly provided by Bastian Blombach (Technical University of Munich, Germany) and Bernhard Eikmanns (University of Ulm, Germany) (Table 1). Both fragments were subcloned together in several steps into pMTL83151. Upstream of kivD, the PCR-amplified $\mathrm{P}_{\text {pta-ack }}$ promoter fragment from C. ljungdahlii (primers: Ptaack_fwd and Ptaack_rev) was inserted. The genes ilvC (encoding ketol-acid reductoisomerase) (primers ilvC_fwd and ilvC_rev), ilvD (encoding dihydroxyacid dehydratase) (primers ilvD_fwd and ilvD_rev), and

TABLE 2 | Primer used for cloning procedures.

\begin{tabular}{|c|c|c|}
\hline Name & Sequence & Amplification \\
\hline clo0020T_fwd & $\begin{array}{l}\text { GATATCTATATAAAATCAT ITAACCTCG } \\
\text { AGAGGAGGATTACCACATGGGCAA }\end{array}$ & $\begin{array}{l}\text { KOR1 } \\
\text { Clo1313_0020- }\end{array}$ \\
\hline clo0020T_rev & 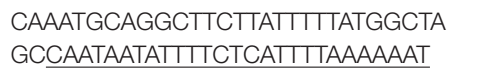 & 0023 \\
\hline clo0382T_fwd & $\begin{array}{l}\text { GATATCTATATAAAATCATITAACCTCG } \\
\text { AGAGGGAGCGATGGAGATGACAGA }\end{array}$ & $\begin{array}{l}\text { KOR2 } \\
\text { Clo1313_0382- }\end{array}$ \\
\hline clo0382T_rev & 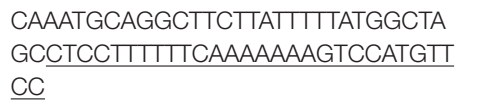 & 0385 \\
\hline clo1353T_fwd & $\begin{array}{l}\text { GATATCTATATAAAATCATПTAACCTCG } \\
\text { AGGGGGGATIACATGGCTAAGGT }\end{array}$ & $\begin{array}{l}\text { KOR3 } \\
\text { Clo1313_1353- }\end{array}$ \\
\hline clo1353T_rev & $\begin{array}{l}\text { CAAATGCAGGCTTCTTATIITATGGCTA } \\
\text { GCCGTATAAGAATTAAAAATAAGAATTA } \\
\underline{\text { AAAATCAAAACAATCAAAAAAAG }}\end{array}$ & 1356 \\
\hline Ptaack_fwd & ACAGCGGCCGCGTCGACGTTACCACTCAT & $P_{\text {pta-ack }}$ \\
\hline Ptaack_rev & ACAACCGGTCCTCAGGTCCTCCCTITA & \\
\hline adhE2_pka_fwd & $\begin{array}{l}\text { ПAAATTAAAGGGAGGACCTGAGGATG } \\
\underline{\text { AAAGTTACAAATCAAAAAGAAC }}\end{array}$ & adhE2 \\
\hline adhE2_pka_rev & $\begin{array}{l}\text { CTTGGGGTGCAGCAGTGGTCATCCTCGAG } \\
\underline{\text { TAAAATGATITATATAGATATCCTTAA }} \\
\underline{\text { GTTC }}\end{array}$ & \\
\hline kivd_fwd_Xhol & CTCGAGGTCCTCCTATITATAAATTATG & kivD \\
\hline kivd_rev_Eco81l & ACACCTGAGGATGTATACAGTAGGAG & \\
\hline adhA_fwd_Xhol & CTCGAGATGACCACTGCTGCACCC & $\operatorname{adh} A$ \\
\hline adhA_rev_Nhel & ACAGCTAGCGCGAGTCGAACAGATGTG & \\
\hline ilvC_fwd & $\begin{array}{l}\text { TGTGGCGATTCGTTCTAACGACGTCAAA } \\
\underline{\text { ATAGTATAAATAAATTATTCAGGAGG }}\end{array}$ & ilvC \\
\hline ilvC_rev & $\begin{array}{l}\text { TGTAAAAAAATACTAGTITACTCATTATC } \\
\underline{\text { AGGATITCATTG }}\end{array}$ & \\
\hline ilvD_fwd & 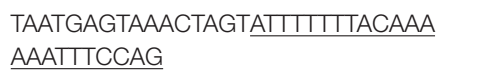 & $i l v D$ \\
\hline ilvD_rev & $\begin{array}{l}\text { GATCTIATACCATGGTTATTAAGAACT } \\
\text { GCACCTGTATTG }\end{array}$ & \\
\hline alsS_fwd & $\begin{array}{l}\text { ПCTTAAATAACCATGGTATAAAGATCAG } \\
\underline{\text { AGGAAGПTIATATG }}\end{array}$ & alss \\
\hline alsS_rev & $\begin{array}{l}\text { CAAAGTAGCTTCAGAGCAGTTCTAGATA } \\
\text { CATATITCATAAAC TCПIIAAATG }\end{array}$ & \\
\hline
\end{tabular}

Underlined nucleotides are vector overlapping fragments used for InFusion ${ }^{\oplus}$ cloning. 
alsS (encoding acetolactate synthase) (primers alsS_fwd and alsS_rev), all from C. ljungdahlii, were PCR-amplified (Table 2). Subcloning downstream of $a d h A$ was performed by in-fusion cloning using the NEBuilder Assembly Tool (New England Biolabs inc., Ipswich, MA, United States; see text footnote 3). The resulting plasmid was designated pKAIA (Supplementary Figure 4).

For changing the coenzyme specificity of IlvC (ketol-acid reductoisomerase) of C. ljungdahlii from $\mathrm{NADPH}$ to $\mathrm{NADH}$, the ilvC $C^{N A D H}$ gene of $E$. coli was commercially synthesized according to Brinkmann-Chen et al. (2013), with appropriate overlaps for in-fusion cloning. Codon optimization for clostridia was suggested by the commercial supplier Thermo Fisher Scientific GENEART GmbH (Regensburg, Germany). The sequence of the codon-optimized, synthesized gene is provided in Supplementary Figure 5.

The ilvC gene was cut out of pKAIA and the codonoptimized, synthesized gene was subcloned into the linearized vector using in-fusion cloning, resulting in plasmid $\mathrm{pKAI}_{\mathrm{NADH}} \mathrm{A}$ (Supplementary Figure 6).

The ClosTron plasmid pMTL007-E2_ilvE (Table 1) was synthesized by the company DNA 2.0 (now ATUM, Newark, CA, United States) (see below).

\section{Transformation}

In case of E. coli, competent cells (Inoue et al., 1990) were obtained by inoculating $250 \mathrm{ml}$ SOB medium with a 5-ml overnight culture grown in the same medium. Incubation was performed in a 2-1 Erlenmeyer flask at $18^{\circ} \mathrm{C}$ under aerobic conditions and shaking (60 rpm), until an optical density $(600 \mathrm{~nm})$ of $0.6-0.8$ was reached. Then, cells were put on ice for $30 \mathrm{~min}$ and afterward centrifuged $\left(4,500 \mathrm{~g}, 4^{\circ} \mathrm{C}, 10 \mathrm{~min}\right)$. The pellet was suspended in $40 \mathrm{ml}$ buffer (per $125 \mathrm{ml}$ : piperazineN,N'-bis(2-ethanesulfonic acid) $0.756 \mathrm{~g}, \mathrm{CaCl}_{2} 0.42 \mathrm{~g}, \mathrm{pH}$ 6.7; mixed with $125 \mathrm{ml}$ containing $4.66 \mathrm{~g} \mathrm{KCl}$ and $1.72 \mathrm{~g}$ $\mathrm{MnCl}_{2} \times 4 \mathrm{H}_{2} \mathrm{O}$ ), incubated on ice for $10 \mathrm{~min}$, and again centrifuged $\left(4,500 \mathrm{~g}, 4^{\circ} \mathrm{C}, 10 \mathrm{~min}\right)$. The pellet was suspended in $10 \mathrm{ml}$ of the same buffer. $1.5 \mathrm{ml}$ sterile dimethyl sulfoxide were added, and the solution was split into $200 \mu \mathrm{l}$ aliquots and stored at $-80^{\circ} \mathrm{C}$. For transformation, such aliquots were thawed on ice, mixed with $10 \mu \mathrm{l}$ of a DNA solution (in-fusion reaction mix or plasmid), incubated on ice for $10 \mathrm{~min}$, and then at $42^{\circ} \mathrm{C}$ for $1 \mathrm{~min}$. After an incubation period of $10 \mathrm{~min}$ again on ice, $800 \mu \mathrm{l} \mathrm{LB}$ medium were added, and the solution was incubated aerobically for $1 \mathrm{~h}$ at $37^{\circ} \mathrm{C}$ with shaking (160 rpm). Then, cells were centrifuged (4,000 g, room temperature, $3 \mathrm{~min}$ ), and $800 \mu \mathrm{l}$ of the supernatant discarded. The pellet was resuspended in the remaining liquid, which was used for plating on solid media with respective selection.

Electroporation of A. woodii and C. ljungdahlii was performed using a modified protocol of Leang et al. (2013). All plastic materials were stored in an anaerobic cabinet at least 1 day before transformation to eliminate any remaining traces of oxygen. For preparation of competent cells, $100 \mathrm{ml}$ medium were supplemented with $40 \mathrm{mM}$ fructose and $40 \mathrm{mM}$ DL-threonine, inoculated with an early exponential culture, and grown at the appropriate temperature to an optical density $(600 \mathrm{~nm})$ of
0.3-0.7. Cultures were centrifuged anaerobically $\left(6,000 \mathrm{~g}, 4^{\circ} \mathrm{C}\right.$, $10 \mathrm{~min}$ ), and the pellet was washed twice with $50 \mathrm{ml}$ cool, anaerobic SMP buffer (per l: sucrose $92.4 \mathrm{~g}, \mathrm{MgCl}_{2} \times 6 \mathrm{H}_{2} \mathrm{O}$ $0.2 \mathrm{~g}, \mathrm{NaH}_{2} \mathrm{PO}_{4} 0.84 \mathrm{~g} ; \mathrm{pH}$ 6) and suspended in $0.6 \mathrm{ml} \mathrm{SMP}$ buffer. $120 \mu \mathrm{l} \mathrm{cool}$ anti-freezing buffer (mix of $20 \mathrm{ml}$ SMP buffer and $30 \mathrm{ml}$ dimethylformamide) were added, and aliquots stored at $-80^{\circ} \mathrm{C}$.

Electroporation was carried out in an anaerobic cabinet. $25 \mu \mathrm{l}$ of electrocompetent cells were mixed with 3-5 $\mu \mathrm{g}$ of plasmid DNA, cooled, and transferred to a pre-cooled 1-mm gap electroporation cuvette (Biozym Scientific GmbH, Hessisch Oldendorf, Germany). Electric pulse was performed with $625 \mathrm{~V}$, resistance of $600 \Omega$, and a capacitance of $25 \mu \mathrm{F}$ using a "GenePulser Xcell ${ }^{\text {TM" }}$ pulse generator (Bio-Rad Laboratories $\mathrm{GmbH}$, Munich, Germany). Afterward, cells were recovered using $5 \mathrm{ml}$ of the respective medium without antibiotic in a Hungate tube and incubated until the optical density $(600 \mathrm{~nm})$ doubled. Then, the appropriate antibiotic was added and growth monitored. If growth was detectable, cells were inoculated into fresh medium with antibiotic and, after reaching the early exponential growth phase, plated onto solid media. Single colonies of obtained transformants were picked, and successful transformation was confirmed by isolating genomic or plasmid DNA and PCR amplification of respective sequences for verification.

\section{Gene Inactivation by ClosTron}

The ClosTron method was performed according to Heap et al. (2007, 2010). The aim was to create an insertion mutant in $i l v E$ of $C$. ljungdahlii, which blocked the last step of valine biosynthesis. Target region for integration was determined using the respective algorithm (Perutka et al., 2004; ${ }^{4}$ ), and the respective ClosTron plasmid (pMTL007-E2_ilvE) (Table 1) was synthesized by the company DNA 2.0 (now ATUM, Newark, CA). After transformation into $C$. ljungdahlii, recombinant strains were verified by PCR amplification and sequencing of the respective gene region.

\section{RESULTS}

\section{Isobutanol Production via Ketoisovalerate Ferredoxin Oxidoreductase (Kor)}

In the genome of $C$. thermocellum three gene clusters are annotated that encode a putative ketoisovalerate ferredoxin oxidoreductase (Kor), i.e., kor1 (Clo1313_0020-0023), kor2 (Clo1313_0382-0385), and kor3 (Clo1313_1353-1356). kor3 differs significantly from the other two clusters with respect to length (smaller) and gene arrangement (Supplementary Figure 7). However, all clusters consist of four genes, encoding the $\alpha, \beta, \gamma$, and $\delta$ subunits of Kor. The $\alpha$ subunit carries the core domain of pyruvate-ferredoxin oxidoreductase, $\beta$ a C-terminal thiamine pyrophosphate-binding domain, $\gamma$ a catalytic domain of pyruvate/ketoisovalerate oxidoreductase, and $\delta$ a binding

\footnotetext{
${ }^{4}$ www.clostron.com
} 
domain for $4 \mathrm{Fe}-4 \mathrm{~S}$ ferredoxin. All clusters were PCR-amplified and subcloned each into the pMTL83151 backbone, together (upstream) with the $\mathrm{P}_{\text {pta-ack }}$ promoter from C. ljungdahlii and the gene encoding bifunctional butyraldehyde/butanol dehydrogenase AdhE2 from C. acetobutylicum. The resulting plasmids (pKOR1, pKOR2, and pKOR3) were transformed into $A$. woodii and C. ljungdahlii. Recombinant strains were then tested under heterotrophic conditions with fructose as a carbon source as well as with and without addition of ketoisovalerate $(15 \mathrm{mM})$. Both, A. woodii and C. ljungdahlii did not grow with ketoisovalerate as sole carbon and energy source and also did not show an increase in optical density when fructose and ketoisovalerate were supplied together, compared to fructose alone. Wild type strains and empty plasmid-carrying strains [A. woodii (pM83) and C. ljungdahlii (pM83)] were used as controls. Without ketoisovalerate addition, recombinant A. woodii strains only formed traces of isobutanol $(0.1 \mathrm{mM})$. However, all pKOR-carrying strains produced increased amounts of ethanol. With addition of ketoisovalerate, A. woodii[pKOR1] produced $0.2 \mathrm{mM}$ isobutanol, $A$. woodii[pKOR2] $0.3 \mathrm{mM}$, and A. woodii[pKOR3] $2.9 \mathrm{mM}$ (Figure 2). Some isoamyl alcohol (up to $0.3 \mathrm{mM}$ ) was formed in addition. The respective data for C. ljungdahlii are shown in Supplementary Figure 8. With and without ketoisovalerate addition, no isobutanol was formed. pKOR-carrying strains produced increased amounts of ethanol with addition of ketoisovalerate.

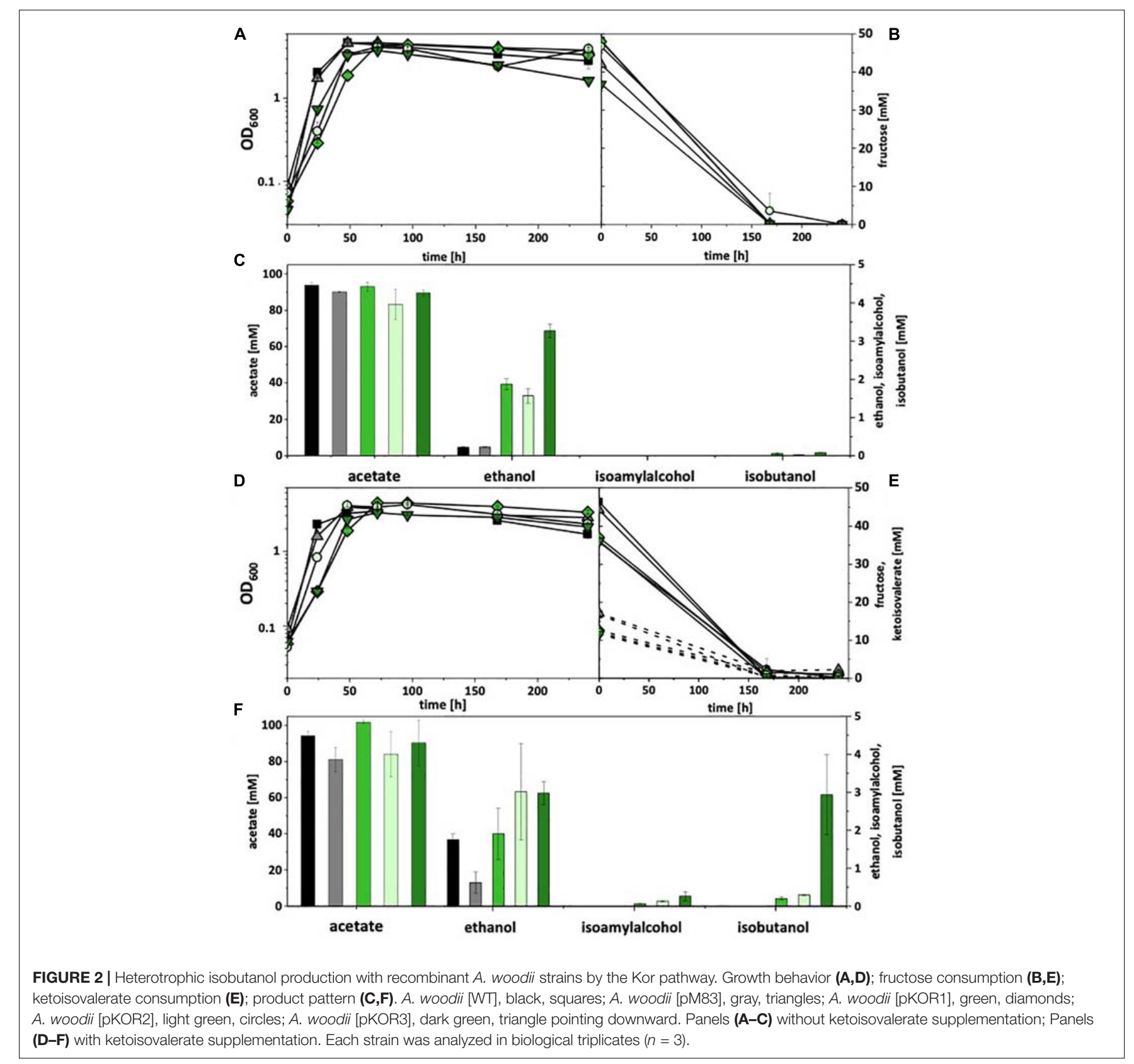




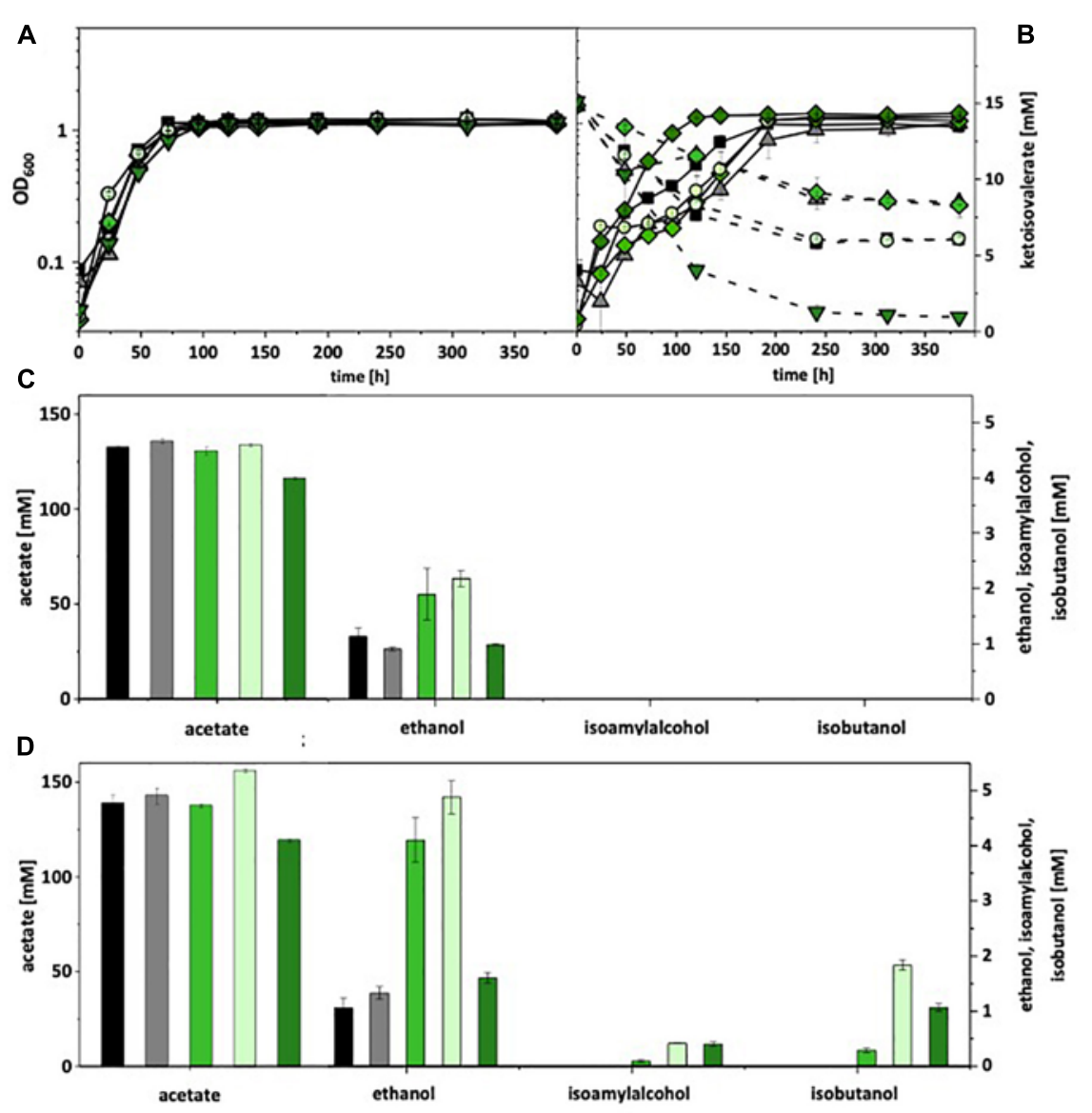

FIGURE 3 | Autotrophic isobutanol production with recombinant $A$. woodii strains by the Kor pathway. Growth behavior (A,B); ketoisovalerate consumption (B); product pattern (C,D). A. woodii [WT], black, squares; A. woodii [pM83], gray, triangles; A. woodii [pKOR1], green, diamonds; A. woodii [pKOR2], light green, circles; A. woodii [pKOR3], dark green, triangle pointing downward. Panels $(\mathbf{A}, \mathbf{C})$ without ketoisovalerate supplementation; Panels $(\mathbf{B}, \mathbf{D})$ with ketoisovalerate supplementation. Each strain was analyzed in biological triplicates $(n=3)$.

For autotrophic growth, A. woodii was cultivated under a $\mathrm{CO}_{2}+\mathrm{H}_{2}$ atmosphere, C. ljungdahlii under syngas. Without ketoisovalerate addition, recombinant $A$. woodii strains formed no isobutanol. With addition, $A$. woodii[pKOR1] produced $0.3 \mathrm{mM}, A$. woodii[pKOR2] $1.8 \mathrm{mM}$, and $A$. woodii[pKOR3] $1.1 \mathrm{mM}$ (Figure 3). A. woodii[pKOR1] and A. woodii[pKOR2] produced also increased amounts of ethanol. Some isoamyl alcohol (up to $0.4 \mathrm{mM}$ ) was formed in addition. The respective data for C. ljungdahlii are shown in Supplementary Figure 9. Without ketoisovalerate addition, no isobutanol was formed and even with addition only trace amounts [C. ljungdahlii(pKOR2) $0.1 \mathrm{mM}$; C. ljungdahlii(pKOR3) $0.2 \mathrm{mM}$ ]. However, C. ljungdahlii[pKOR3] showed a significant increase in ethanol formation without ketoisovalerate addition as well as C. ljungdahlii[pKOR2] with addition.

\section{Isobutanol Production via Ketoisovalerate Decarboxylase (KivD)}

Next, the isobutanol synthesis pathway via ketoisovalerate decarboxylase and alcohol dehydrogenase in acetogens was elucidated. The kivD gene from L. lactis and adhA from C. glutamicum were PCR-amplified and subcloned together into the pMTL83151 backbone, controlled by the also PCRamplified $\mathrm{P}_{\text {pta-ack }}$ promoter from C. ljungdahlii. In order to increase the carbon flux from pyruvate to ketoisovalerate, genes $i l v C$ (encoding ketol-acid reductoisomerase), ilvD (encoding dihydroxy-acid dehydratase), and alsS (encoding acetolactate synthase), all from C. ljungdahlii, were PCR-amplified and subcloned downstream of adhA. The resulting plasmid pKAIA was transformed into $A$. woodii and $C$. ljungdahlii. In case of $C$. ljungdahlii, it was also possible to construct an insertion mutant in ilvE (encoding an aminotransferase), which blocked the last step of valine biosynthesis. This strain, C. ljungdahlii:ilvE was also transformed with pKAIA. Recombinant strains were then tested under heterotrophic conditions with fructose as a carbon source as well as with and without addition of ketoisovalerate $(15 \mathrm{mM})$. Wild type strains and empty plasmid-carrying strains were used as controls. Without ketoisovalerate addition, only $A$. woodii[pKAIA] formed some isobutanol $(0.2 \mathrm{mM})$. With addition, the same strain produced $0.4 \mathrm{mM}$ (Supplementary Figure 10). Some 


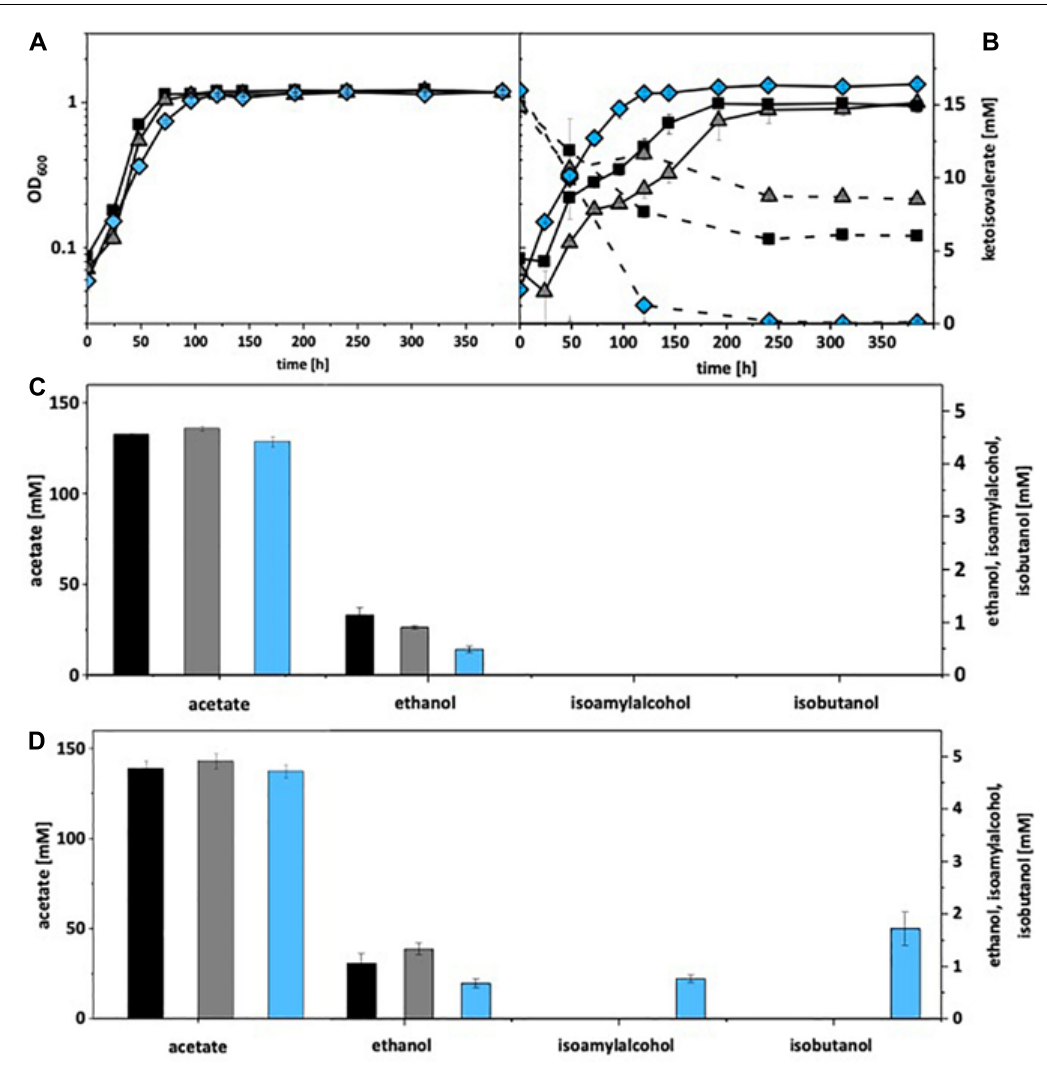

FIGURE 4 | Autotrophic isobutanol production with recombinant $A$. woodii strains by the KivD pathway. Growth behavior (A,B); ketoisovalerate consumption (B); product pattern (C,D). A. woodii [WT], black, squares; A. woodii [pM83], gray, triangles; A. woodii [pKAIA], blue, diamonds. Panels $(\mathbf{A}, \mathbf{C})$ without ketoisovalerate supplementation; Panels $\mathbf{( B , D )}$ with ketoisovalerate supplementation. Each strain was analyzed in biological triplicates $(n=3)$.

isoamyl alcohol (up to $0.2 \mathrm{mM}$ ) was formed in addition. The respective data for C. ljungdahlii are shown in Supplementary Figure 11. Without ketoisovalerate addition, no isobutanol was formed. With addition, C. ljungdahlii[pKAIA] and C. ljungdahlii:ilvE[pKAIA] produced up to $2.4 \mathrm{mM}$ isobutanol during the exponential growth phase.

Under autotrophic growth conditions, recombinant $A$. woodii strains formed no isobutanol. With addition of $15 \mathrm{mM}$ isovalerate, A. woodii[pKAIA] produced $1.7 \mathrm{mM}$ isobutanol and $0.8 \mathrm{mM}$ isoamyl alcohol (Figure 4). The respective data for C. ljungdahlii are shown in Figure 5. Only C. ljungdahlii[pKAIA] and C. ljungdahlii:ilvE[pKAIA] formed isobutanol (and isoamyl alcohol) without ketoisovalerate addition. The latter strain formed three times more acohols (up to $0.4 \mathrm{mM}$ isobutanol). Addition of ketoisovalerate increased production of both alcohols in the pKAIA-carrying strains (up to $1 \mathrm{mM}$ in C. ljungdahlii:ilvE[pKAIA]).

\section{Coenzyme Dependency of Isobutanol Production via Ketoisovalerate Decarboxylase (KivD)}

The ilvC gene product of $C$. ljungdahlii, the ketol-acid reductoisomerase, uses NADPH for reduction of acetolactate to 2,3-dihydroxyisovalerate. However, NADPH might be a limiting factor in a catabolic pathway with high amounts of products. Therefore, this gene in pKAIA was replaced by a similar gene encoding a NADH-dependent IlvC enzyme from E. coli (Brinkmann-Chen et al., 2013). The nucleotide sequence of Ec_IlvC $C^{P 2 D 1-A 1}$ was codon-optimized for clostridia, PCR-amplified, and subcloned into pKAIA by replacing the C. ljungdahlii ilvC gene. The resulting plasmid was designated $\mathrm{pKAI}_{\mathrm{NADH}} \mathrm{A}$ (Supplementary Figure 6). This plasmid was transformed into C. ljungdahlii:ilvE, and the recombinant tested in heterotrophic and autotrophic fermentations. With fructose as a carbon source, C. ljungdahlii:ilvE[pKAI $\mathrm{NADH}_{\mathrm{NA}} \mathrm{A}$ produced isobutanol only upon addition of ketoisovalerate. The production was slightly higher than with the corresponding pKAIA-carrying strain (1.6 vs. $1.4 \mathrm{mM}$ ). Under autotrophic conditions without isovalerate supplementation, C. ljungdahlii:ilvE[pKAI $\left.\mathrm{NADH}_{\mathrm{H}} \mathrm{A}\right]$ formed only trace amounts of isobutanol $(0.1 \mathrm{mM})$. Even with isovalerate addition, lower amounts were produced than by C. ljungdahlii:ilvE[pKAIA] (0.8 $\mathrm{mM}$ compared to $1 \mathrm{mM})$.

\section{DISCUSSION}

The data presented clearly demonstrate that subcloning of both, the KivD as well as the Kor pathway lead to heterologous expression of isobutanol formation in acetogenic bacteria. Both 


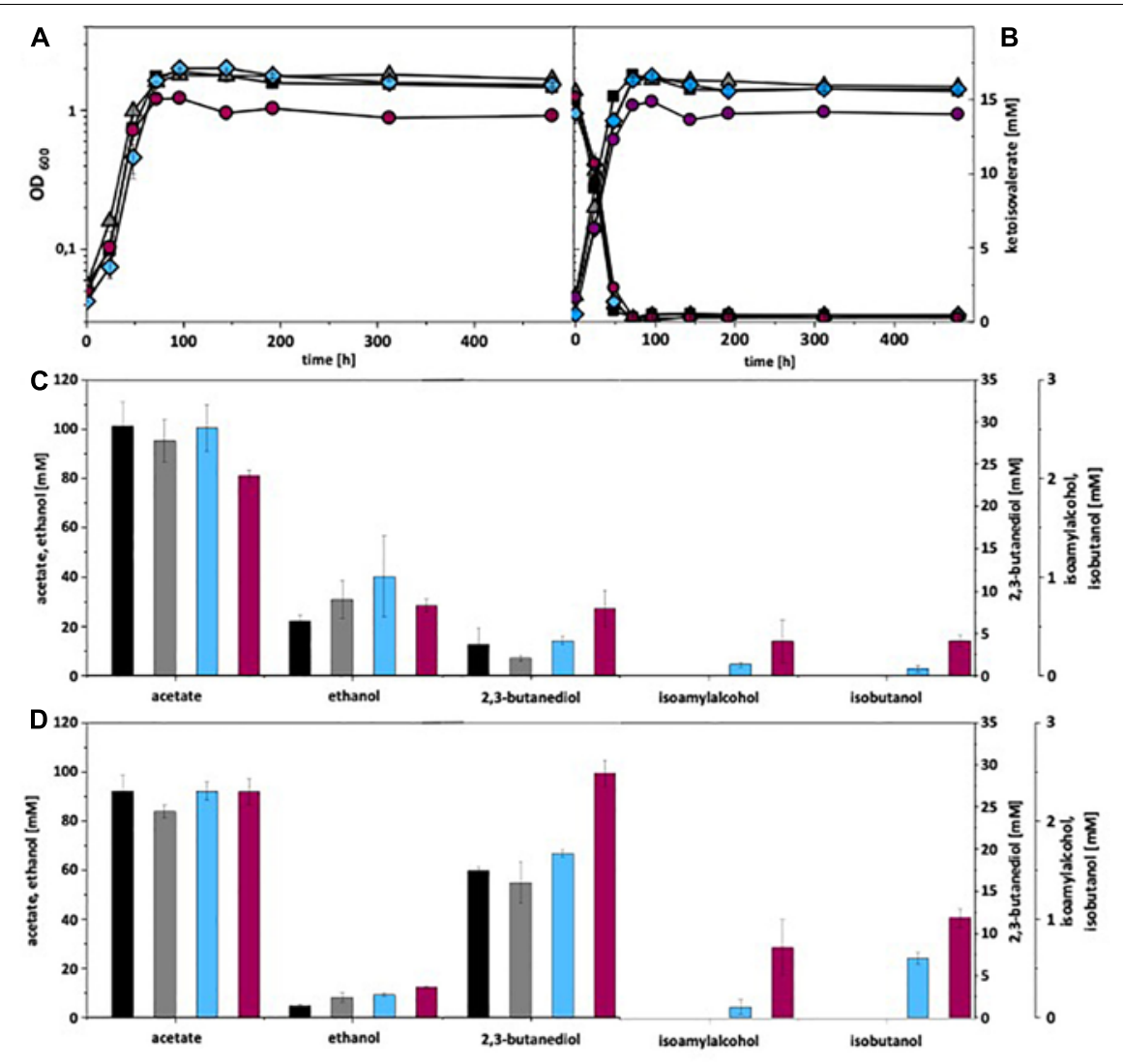

FIGURE 5 | Autotrophic isobutanol production with recombinant C. ljungdahlii strains by the KivD pathway. Growth behavior (A,B); ketoisovalerate consumption (B) product pattern (C,D). C. ljungdahlii [WT], black, squares; C. ljungdahlii [pM83], gray, triangles; C. ljungdahlii [pKAIA], blue, diamonds; C. ljungdahlii:ilvE [pKAIA], purple, circles; Panels (A,C) without ketoisovalerate supplementation; Panels (B,D) with ketoisovalerate supplementation. Each strain was analyzed in biological triplicates $(n=3)$.

key enzymes, ketoisovalerate decarboxylase and ketoisovalerate ferredoxin oxidoreductase, belong to the group of pyruvate decarboxylases/pyruvate oxidoreductases and are dependent on thiamine pyrophosphate (Heider et al., 1996; de la Plaza et al., 2004). The active forms are homo- or heterotetramers, respectively. KivD from $L$. lactis decarboxylates preferentially ketoisovalerate, but also showed specific activity toward other keto compounds, from ketoisocaproate (23\% relative activity) to pyruvate ( $0.6 \%$ relative activity) (de la Plaza et al., 2004). The temperature optimum is $45^{\circ} \mathrm{C}$, but more than $74 \%$ relative activity is found between 30 and $50^{\circ} \mathrm{C}$ (de la Plaza et al., 2004). The $\mathrm{pH}$ optimum is more pronounced, with a peak at $\mathrm{pH} 6.5$ and app. 90\% relative activity between $\mathrm{pH} 6$ and 7 (de la Plaza et al., 2004). Kor has been purified from Pyrococcus and Thermococcus strains, which are proteolytic and hyperthermophilic archaea. Highest activity was observed with ketoisovalerate, lowest activity with phenylpyruvate, pyruvate, and glyoxylate (Heider et al., 1996). Based on the back reaction of acetyl-CoA $+\mathrm{CO}_{2}+$ reduced ferredoxin to pyruvate, Xiong et al. (2016) characterized the kor gene clusters of C. thermocellum as reversed pyruvate ferredoxin oxidoreductases. T. litoralis Kor exhibits a sharp $\mathrm{pH}$ optimum at 7 , with less than $50 \%$ relative activity of pH 6 and 25\% at pH 8 (Heider et al., 1996). The temperature optimum of enzymes from the different archaea varies between 90 and $98^{\circ} \mathrm{C}$ (Heider et al., 1996).

Our results demonstrate that the kor3 and kor2 gene clusters are the best suited candidates for further improvement of isobutanol production in acetogens by the Kor pathway, especially in $A$. woodii. Interestingly, the relatively low similarity between the respective gene products (Supplementary Figure 7) does not show a massive effect on product formation. Although the titers are still low $(0.1 \mathrm{mM}$ without and up to $2.9 \mathrm{mM}$ with ketoisovalerate addition), it must be kept in mind that in other reported production organisms such as E. coli and C. glutamicum only numerous additional gene inactivations finally led to promising strains (Atsumi et al., 2008; Blombach et al., 2011). The formation of isoamyl alcohol (3-methyl-1butanol) is most probably due to the relatively broad substrate spectrum of ketoisovalerate ferredoxin oxidoreductase (and also ketoisovalerate decarboxylase) (Heider et al., 1996; Atsumi et al., 2008). Ketoisocaproate would be the precursor and is metabolized by both enzymes. This substance is formed naturally during leucine biosynthesis. Interestingly, the introduction of the kor 1 and kor2 gene clusters led in both, A. woodii and C. ljungdahlii to an app. doubling of the ethanol formation, but only under autotrophic conditions upon addition of 
ketoisovalerate. kor2 in A. woodii under heterotrophic conditions resulted in the same phenomenon, whereas in C. ljungdahlii rather a decrease in ethanol formation in kor-carrying strains under heterotrophic conditions could be observed. The reason for this phenomenon is not obvious, as especially in A. woodii the stoichiometry of added ketoisovalerate and formed ethanol does not match. On the other hand, the increase of 2,3butanediol production in all C. ljungdahlii strains upon addition of ketoisovalerate can be easily explained. Obviously, ketoisovalerate was converted to acetolactate, which was then decarboxylated and reduced to yield 2,3-butanediol.

The KivD pathway also allowed formation of trace amounts of isobutanol in A. woodii (heterotrophic conditions) and $C$. ljungdahlii (autotrophic conditions). Addition of ketoisovalerate clearly stimulated isobutanol production in both organisms under all tested growth conditions. The inactivation of $i l v E$ in $C$. ljungdahlii (blocking the last step of valine biosynthesis) led to a significant increase in isobutanol production. This stresses again the necessity of further tailored metabolic mutations for optimizing the isobutanol fermentation. Unfortunately, an attempt during this project to inactivate the aldC gene of $C$. ljungdahlii (encoding the acetolactate decarboxylase, which catalyzes the first step of 2,3-butanediol synthesis) failed. Such a mutant would have prevented the carbon flow toward 2,3-butanediol. It was also disappointing that changing the coenzyme specificity of IlvC, the ketol-acid reductoisomerase, of $C$. ljungdahlii from NADPH to NADH did not result in an increase in isobutanol formation. However, as already stressed before, most probably only a combination of a series of metabolic alterations will result in a suitable production strain, as was the case with other heterotrophic bacteria.

What targets for such mutations can be imagined? Of course, reduction of other products will be the primary goal. Acetate formation is of vital importance for acetogens regarding ATP formation, but it can be further converted to ethanol using aldehyde ferredoxin oxidoreductase and alcohol dehydrogenase. The required reducing equivalents (reduced ferredoxin and $\mathrm{NADH}$ ) can be easily generated from hydrogen under autotrophic conditions. Thus, 2,3butanediol is the prime candidate for a product to be eliminated. If the ClosTron technology does not work (as mentioned, our attempt to inactivate the ilvC gene failed), CRISPR/Cas9-based genome editing will be an alternative that has recently been developed for C. ljungdahlii (Huang et al., 2016; Jin et al., 2020). The optimal temperatures for both key enzymes, ketoisovalerate decarboxylase $\left(45^{\circ} \mathrm{C}\right)$ and ketoisovalerate ferredoxin oxidoreductase (growth temperature of $C$. thermocellum is $60^{\circ} \mathrm{C}$ ), significantly exceed the range of mesophilic fermentations. The same applies to the $\mathrm{pH}$ optimum of both enzymes. Acetogenic bacteria generate a low $\mathrm{pH}$, which results in reduced enzyme activity. Also, the broad enzyme substrate range is a disadvantage, as is obvious from the formation of isoamyl alcohol by $A$. woodii. Thus, mutational adaptation of the key enzymes with respect to $\mathrm{pH}$ and temperature tolerance as well as increase of substrate specificity will be another prime target in future. The change of coenzyme specificity from NADPH to NADH has already been achieved for IlvC from C. ljungdahlii and can thus easily be combined with the aforementioned alterations. The benefit of a NADH-depending alcohol dehydrogenase replacement in the natural, decarboxylase-based isobutanol formation pathway of Shimwellia blattae has recently been shown by Acedos et al. (2021). Finally, growing the strains in gassed and stirred bioreactors will certainly improve the fermentation outcome. In fact, a $C$. ljungdahlii:ilvE strain carrying pKAIA showed under such conditions an increased isobutanol production by factor 6.5 (Hermann et al., 2021).

Further metabolic engineering will focus on the kor3 gene cluster in case of $A$. woodii and the KivD pathway in C. ljungdahlii:ilvE[pKAIA], which so far allowed highest product formation. Strains suitably improved as described above might then become a viable option for commercial isobutanol synthesis from waste and greenhouse gases such as $\mathrm{CO}$ and $\mathrm{CO}_{2}$.

\section{DATA AVAILABILITY STATEMENT}

The original contributions presented in the study are included in the article/Supplementary Material, further inquiries can be directed to the corresponding author/s.

\section{AUTHOR CONTRIBUTIONS}

SW, FB, MH, RT, and PD conceived and designed the experiments. SW and SL performed the experiments. SW, $\mathrm{MH}$, SL, FB, RT, and PD analyzed the data. MH, SL, FB, RT, and PD wrote the manuscript. All authors contributed to the article and approved the submitted version.

\section{FUNDING}

This work was supported by the Bundesministerium für Bildung und Forschung (BMBF) in its program "Gase als neue Kohlenstoffquelle für biotechnologische Fermentationen," project gas fermentation (031A468A).

\section{ACKNOWLEDGMENTS}

We thank Nigel Minton (University of Nottingham, United Kingdom) for providing plasmid pMTL83151 and Bastian Blombach (Technical University of Munich, Germany) as well as Bernhard Eikmanns (University of Ulm, Germany) for providing plasmid pJUL34.

\section{SUPPLEMENTARY MATERIAL}

The Supplementary Material for this article can be found online at: https://www.frontiersin.org/articles/ 10.3389/fbioe.2021.657253/full\#supplementary-material 
Supplementary Figure 1 | Schematic representation of plasmid pMTL83151_ptaack_aacht_cac. adhE2, bifunctional aldehyde/alcohol dehydrogenase gene (C. acetobutylicum); abfD, 4-hydroxybutyryl-CoA dehydratase gene (Clostridium scatologenes); crt, crotonase gene (C. acetobutylicum); hbd, 3-hydroxybutyryl-CoA dehydrogenase gene (C. acetobutylicum); thIA, acetyl-CoA acetyltransferase gene (C. acetobutylicum); catP, chloramphenicol resistance gene; ColE1, origin of replication for Gram-negative bacteria; repH, origin of replication for Gram-positive bacteria; lacZ alpha, truncated $\beta$-galactosidase gene ( $E$. coll); traJ, gene for DNA transfer by conjugation.

Supplementary Figure 2 | Schematic representation of plasmids pKOR1, pKOR2, and pKOR3. kor1, kor2, kor3, potential ketoisovalerate ferredoxin oxidoreductases gene clusters (C. thermocellum); adhE2, bifunctional aldehyde/alcohol dehydrogenase gene (C. acetobutylicum); $P_{\text {pta-ack, }}$ promoter upstream of pta-ack genes (C. ljungdahlii); catP, chloramphenicol resistance gene; ColE1, origin of replication for Gram-negative bacteria; repH, origin of replication for Gram-positive bacteria; traJ, gene for DNA transfer by conjugation.

Supplementary Figure $\mathbf{3}$ | Schematic representation of plasmid pJUL34. Ptuf, promoter upstream of EF-Tu gene (L. lactis); kivD, ketoisovalerate decarboxylase gene (L. lactis); adhA, alcohol dehydrogenase gene (Corynebacterium glutamicum); lacZ alpha, truncated $\beta$-galactosidase gene (E. coli); aph3, kanamycin resistance gene; $s a c B$, levansucrase gene; repBL1, origin of replication for Corynebacterium.

Supplementary Figure 4 | Schematic representation of plasmid pKAIA. kivD, ketoisovalerate decarboxylase gene (L. lactis); adhA, alcohol dehydrogenase gene (C. glutamicum); ilvC, ketol-acid reductoisomerase gene (C. ljungdahlii); ilvD, dihydroxy-acid dehydratase gene (C. ljungdahlii); alsS, acetolactate synthase gene (C. ljungdahlii); $P_{\text {pta-ack, }}$ promoter upstream of pta-ack genes (C. ljungdahlii); catP, chloramphenicol resistance gene; ColE1, origin of replication for Gram-negative bacteria; repH, origin of replication for Gram-positive bacteria; traJ, gene for DNA transfer by conjugation.

Supplementary Figure $\mathbf{5} \mid$ Sequence of the commercially synthesized and codon-optimized il $C^{N A D H}$ gene.

Supplementary Figure 6 | Schematic representation of plasmid pKAl $\left.\right|_{N A D H} A$. kivD, ketoisovalerate decarboxylase gene (L. lactis); adhA, alcohol dehydrogenase gene (Corynebacterium g/utamicum); ilvC, ketol-acid reductoisomerase gene (C. ljungdahlii); i IVC $\mathrm{NADH}$, NADH-dependent ketol-acid reductoisomerase gene (Ec_llvCP2D1-A1 from E. coli, codon-optimized for clostridia); ilvD, dihydroxy-acid

\section{REFERENCES}

Acedos, M. G., de la Torre, I., Santos, V. E., García-Ochoa, F., García, J. L., and Galán, B. (2021). Modulating redox metabolism to improve isobutanol production in Shimwellia blattae. Biotechnol. Biofuels 14, 1-11. doi: 10.1186/ s13068-020-01862-1

Atsumi, S., Hanai, T., and Liao, J. C. (2008). Non-fermentative pathways for synthesis of branched-chain higher alcohols as biofuels. Nature 451, 86-89. doi: 10.1038/nature06450

Balch, W. E., Schoberth, S., Tanner, R. S., and Wolfe, R. S. (1977). Acetobacterium, a new genus of hydrogen-oxidizing, carbon dioxide-reducing, anaerobic bacteria. Int. J. Syst. Bacteriol. 27, 355-361.

Black, W. B., Zhang, L., Kamoku, C., Liao, J. C., and Li, H. (2018). Rearrangement of coenzyme A-acylated carbon chain enables synthesis of isobutanol via a novel pathway in Ralstonia eutropha. ACS Synth. Biol. 7, 794-800. doi: 10.1021/ acssynbio.7b00409

Blombach, B., Riester, T., Wieschalka, S., Ziert, C., Youn, J.-W., Wendisch, V. F., et al. (2011). Corynebacterium glutamicum tailored for efficient isobutanol production. Appl. Environ. Microbiol. 77, 3300-3310. doi: 10.1128/AEM.029 $72-10$

Brigham, C. (2019). Perspectives for the biotechnological production of biofuels from $\mathrm{CO}_{2}$ and $\mathrm{H}_{2}$ using Ralstonia eutropha and other 'Knallgas' bacteria. Appl. Microbiol. Biotechnol. 103, 2113-2120. doi: 10.1007/s00253-01909636-y dehydratase gene (C. ljungdahlii); alsS, acetolactate synthase gene (C. ljungdahlii); $P_{\text {pta-ack, }}$ promoter upstream of pta-ack genes (C. ljungdahlii); catP, chloramphenicol resistance gene; ColE1, origin of replication for Gram-negative bacteria; repH, origin of replication for Gram-positive bacteria; traJ, gene for DNA transfer by conjugation.

Supplementary Figure 7 | tBLASTx comparison of gene clusters Clo1313_0020-0023 [kor1], Clo1313_0382-0385 [kor2], and Clo1313_1353-1356 [kor3] from C. thermocellum.

Supplementary Figure 8 | Heterotrophic isobutanol production with recombinant C. ljungdahlii strains by the Kor pathway. Growth behavior $(\mathbf{A}, \mathbf{D})$; fructose consumption (B,E); ketoisovalerate consumption (E); product pattern (C,F). C. ljungdahlii [WT], black, squares; C. ljungdahlii [pM83], gray, triangles; C. ljungdahlii [pKOR1], green, diamonds; C. ljungdahlii [pKOR2], light green, circles; C. ljungdahlii [pKOR3], dark green, triangle pointing downward. Panels (A-C) without ketoisovalerate supplementation; Panels (D-F) with ketoisovalerate supplementation. Each strain was analyzed in biological triplicates $(n=3)$.

Supplementary Figure 9 | Autotrophic isobutanol production with recombinant C. ljungdahlii strains by the Kor pathway. Growth behavior (A,B); ketoisovalerate consumption (B); product pattern (C,D). C. ljungdahlii [WT], black, squares; C. ljungdahlii [pM83], gray, triangles; C. ljungdahlii [pKOR1], green, diamonds; C. ljungdahlii [pKOR2], light green, circles; C. ljungdahlii [pKOR3], dark green, triangle pointing downward. Panels $(\mathbf{A}, \mathbf{C})$ without ketoisovalerate supplementation; Panels (B,D) with ketoisovalerate supplementation. Each strain was analyzed in biological triplicates $(n=3)$.

Supplementary Figure $\mathbf{1 0} \mid$ Heterotrophic isobutanol production with recombinant $A$. woodii strains by the KivD pathway. Growth behavior (A,D); fructose consumption $(\mathbf{B}, \mathbf{E})$; ketoisovalerate consumption $\mathbf{( E )}$; product pattern (C,F). A. woodii [WT], black, squares; A. woodii [pM83], gray, triangles; A. woodii [pKAIA], blue, diamonds. Panels (A-C) without ketoisovalerate supplementation; Panels (D-F), with ketoisovalerate supplementation. Each strain was analyzed in biological triplicates $(n=3)$.

Supplementary Figure 11 | Heterotrophic isobutanol production with recombinant $C$. ljungdahlii strains by the KivD pathway. Growth behavior $(\mathbf{A}, \mathbf{D})$; fructose consumption (B,E); ketoisovalerate consumption $(\mathbf{E})$; product range (C,F). C. ljungdahlii [WT], black, squares; C. ljungdahlii [pKAIA], blue, diamonds; C. ljungdahlii:ilvE [pKAIA], purple, circles. Panels (A-C) without ketoisovalerate supplementation; Panels (D-F) with ketoisovalerate supplementation. Each strain was analyzed in biological triplicates $(n=3)$.

Brinkmann-Chen, S., Flock, T., Cahn, J. K. B., Snow, C. D., Brustad, E. M., McIntosh, J. A., et al. (2013). General approach to reversing ketol-acid reductoisomerase cofactor dependence from NADPH to NADH. Proc. Natl. Acad. Sci. U.S.A. 110, 10946-10951. doi: 10.1073/pnas.1306073110

Chen, C.-T., and Liao, J. C. (2016). Frontiers in microbial 1-butanol and isobutanol production. FEMS Microbiol. Lett. 363:fnw020. doi: 10.1093/femsle/fnw020

de la Plaza, M., de Palencia, P. F., Peláez, C., and Requena, T. (2004). Biochemical and molecular characterization of $\alpha$-ketoisovalerate decarboxylase, an enzyme involved in the formation of aldehydes from amino acids by Lactococcus lactis. FEMS Microbiol. Lett. 238, 367-374. doi: 10.1016/j.femsle.2004.07.057

Green, M., and Sambrook, J. (2012). Molecular Cloning: a Laboratory Manual. Cold Spring Harbor, NY: Cold Spring Harbor Laboratory Press.

Heap, J. T., Kuehne, S. A., Ehsaan, M., Cartman, S. T., Cooksley, C. M., Scott, J. C., et al. (2010). The ClosTron: mutagenesis in Clostridium refined and streamlined. J. Microbiol. Methods 80, 49-55. doi: 10.1016/j.mimet.2009.10.018

Heap, J. T., Pennington, O. J., Cartman, S. T., Carter, G. P., and Minton, N. P. (2007). The ClosTron: a universal gene knock-out system for the genus Clostridium. J. Microbiol. Methods 70, 452-464. doi: 10.1016/j.mimet.2007.05. 021

Heap, J. T., Pennington, O. J., Cartman, S. T., and Minton, N. P. (2009). A modular system for Clostridium shuttle plasmids. J. Microbiol. Methods 78, 79-85. doi: 10.1016/j.mimet.2009.05.004

Heider, J., Mai, X., and Adams, M. W. W. (1996). Characterization of 2ketoisovalerate ferredoxin oxidoreductase, a new and reversible coenzyme 
A-dependent enzyme involved in peptide fermentation by hyperthermophilic archaea. J. Bacteriol. 178, 780-787.

Hermann, M., Teleki, A., Weitz, S., Niess, A., Freund, A., Bengelsdorf, F. R., et al. (2021). Debottlenecking autotrophic isobutanol formation in recombinant C. ljungdahlii by systemic analysis. Front. Bioeng. Biotechnol. 9:647853. doi: 10.3389/fbioe.2021.647853

Huang, H., Chai, C., Li, N., Rowe, P., Minton, N. P., Yang, S., et al. (2016). CRISPR/Cas9-based efficient genome editing in Clostridium ljungdahlii, an autotrophic gas-fermenting bacterium. ACS Synth. Biol. 5, 1355-1361. doi: 10.1021/acssynbio.6b00044

Inoue, H., Nojima, H., and Okayama, H. (1990). High efficiency transformation of Escherichia coli with plasmids. Gene 96, 23-28. doi: 10.1016/0378-1119(90) 90336- $\mathrm{p}$

Jin, S., Bae, J., Song, Y., Pearcy, N., Shin, J., Kang, S., et al. (2020). Synthetic biology on acetogenic bacteria for highly efficient conversion of $\mathrm{C} 1$ gases to biochemicals. Int. J. Mol. Sci. 21:7639. doi: 10.3390/ijms21207639

Leang, C., Ueki, T., Nevin, K. P., and Lovley, D. R. (2013). A genetic system for Clostridium ljungdahlii: a chassis for autotrophic production of biocommodities and a model homoacetogen. Appl. Environ. Microbiol. 79, 1102-1109. doi: 10. 1128/AEM.02891-12

Li, H., Opgenorth, P. H., Wernick, D. G., Rogers, S., Wu, T.-Y., Higashide, W., et al. (2012). Integrated electromicrobial conversion of $\mathrm{CO}_{2}$ to higher alcohols. Science 335:1596. doi: 10.1126/science. 1217643

Lin, P. P., Mi, L., Morioka, A. H., Yoshino, K. M., Konishi, S., Xu, S. C., et al. (2015). Consolidated bioprocessing of cellulose to isobutanol using Clostridium thermocellum. Metab. Eng. 31, 44-52. doi: 10.1016/j.ymben.2015.07.001

Lin, P. P., Rabe, K. S., Takasumi, J. L., Kadisch, M., Arnold, F. H., and Liao, J. C. (2014). Isobutanol production at elevated temperatures in thermophilic Geobacillus thermoglucosidasius. Metab. Eng. 24, 1-8. doi: 10.1016/j.ymben. 2014.03.006
Miao, R., Xie, H., and Lindblad, P. (2018). Enhancement of photosynthetic isobutanol production in engineered cells of Synechocystis PCC 6803. Biotechnol. Biofuels 11:267. doi: 10.1186/s13068-018-1268-8

Perutka, J., Wang, W., Goerlitz, D., and Lambowitz, A. M. (2004). Use of computerdesigned group II introns to disrupt Escherichia coli DExH/D-box protein and DNA helicase genes. J. Mol. Biol. 336, 421-439. doi: 10.1016/j.jmb.2003.12. 009

Tanner, R. S., Miller, L. M., and Yang, D. (1993). Clostridium ljungdahlii sp. nov., an acetogenic species in clostridial rRNA homology group I. Int. J. Syst. Bacteriol. 43, 232-236. doi: 10.1099/00207713-43-2-232

Wess, J., Brinek, M., and Boles, E. (2019). Improving isobutanol production with the yeast Saccharomyces cerevisiae by successively blocking competing metabolic pathways as well as ethanol and glycerol formation. Biotechnol. Biofuels 12:173. doi: 10.1186/s13086-019-1486-8

Xiong, W., Lin, P. P., Magnusson, L., Warner, L., Liao, J. C., Maness, P.-C., et al. (2016). $\mathrm{CO}_{2}$-fixing one-carbon metabolism in a cellulose-degrading bacterium Clostridium thermocellum. Proc. Natl. Acad. Sci. U.S.A. 113, 13180-13185. doi: $10.1073 /$ pnas. 1605482113

Conflict of Interest: The authors declare that the research was conducted in the absence of any commercial or financial relationships that could be construed as a potential conflict of interest.

Copyright $\odot 2021$ Weitz, Hermann, Linder, Bengelsdorf, Takors and Dürre. This is an open-access article distributed under the terms of the Creative Commons Attribution License (CC BY). The use, distribution or reproduction in other forums is permitted, provided the original author(s) and the copyright owner(s) are credited and that the original publication in this journal is cited, in accordance with accepted academic practice. No use, distribution or reproduction is permitted which does not comply with these terms. 